\title{
Structural dynamic response of an unreinforced masonry house using non-destructive forced vibration
}

\author{
A. R. Abdul Karim ${ }^{1}$, N. M.Sa'don ${ }^{2}$, and J. M. Ingham ${ }^{3}$
}

1. Corresponding Author: Senior Lecturer, Department of Civil Engineering, Faculty of Engineering, University of Malaysia Sarawak (UNIMAS), 94300 Kota Samarahan, Sarawak, Malaysia. Email: akarazak@feng.unimas.my

2. Senior Lecturer, Department of Civil Engineering, Faculty of Engineering, University of Malaysia Sarawak (UNIMAS), 94300 Kota Samarahan, Sarawak, Malaysia. Email: msazzlin@feng.unimas.my

3. Professor, Department of Civil \& Environmental Engineering, The University of Auckland, Private Bag 92019, Auckland 1142, New Zealand. Email: j.ingham@auckland.ac.nz

\begin{abstract}
The results of non-destructive forced vibration tests on a small-scale unreinforced masonry house with a flexible timber diaphragm are presented. The primary purpose of this study was to investigate the dynamic responses between the as-built and retrofitted structures. This includes assessment of diaphragm response, wall-diaphragm connection details, in-plane wall response, out-of-plane wall response, and the response of wall corners. The test protocols were designed to investigate two types of retrofit techniques consisting of a plywood-retrofit on the diaphragm, and a connection-retrofit between the wall and diaphragm. From the results, one can see that the natural frequency and mode shapes of the first translational mode were affected. The force transfer mechanism of the as-built structure was significantly improved after applying both retrofits whereas each technique shows distinctive enhancements on the structure overall response.
\end{abstract}

Keywords: unreinforced masonry, structural response, dynamic response, non-destructive, forced vibration

\section{INTRODUCTION}

Unreinforced masonry buildings have long been recognised to perform poorly in an earthquake. This deficient performance was clearly demonstrated in several major earthquake episodes such as the 1931 Hawke's Bay (Dowrick 1998; Blaikie and Spurr 1992) and 1989 Loma Prieta (Bruneau 1994a; Bruneau 1994b) earthquakes. Due to their poor performance in past earthquakes, an understanding of the structural dynamic behaviour of unreinforced masonry buildings when subjected to seismic excitation is of main interest in many seismically active countries such as the United States, New Zealand, Italy, Portugal and Chile. In New Zealand, the requirement to seismically upgrade these earthquake-prone buildings was mandated by The Building Act 2004 (DBH 2004). Importantly, these buildings form a significant percentage of New Zealand's building stock and represent the predominant national architectural heritage (Russell and Ingham 2008).

Most unreinforced masonry buildings in New Zealand consist of solid unreinforced masonry bearing walls and flexible timber floor and roof diaphragms. The wall thickness configuration over the height of the building was typically reduced by a single leaf at each storey height to support the diaphragm. No connections between walls and diaphragm were observed in the 